\title{
openheart Adaptive servoventilation versus oxygen therapy for sleep disordered breathing in patients with heart failure: a randomised trial
}

Kimihiko Murase, ${ }^{1}$ Koh Ono, ${ }^{2}$ Tomoya Yoneda, ${ }^{3}$ Moritake Iguchi, ${ }^{4}$ Takafumi Yokomatsu, ${ }^{5}$ Tetsu Mizoguchi, ${ }^{5}$ Toshiaki Izumi, ${ }^{6}$ Masaharu Akao, ${ }^{4}$ Shinji Miki, ${ }^{5}$ Ryuji Nohara, ${ }^{6}$ Kenji Ueshima, ${ }^{7}$ Michiaki Mishima, ${ }^{1}$ Takeshi Kimura, ${ }^{3}$ David P White, ${ }^{8}$ Kazuo Chin ${ }^{9}$

To cite: Murase K, Ono K, Yoneda T, et al. Adaptive servoventilation versus oxygen therapy for sleep disordered breathing in patients with heart failure: a randomised trial. Open Heart 2016;3:e000366. doi:10.1136/openhrt-2015000366

- Additional material is available. To view please visit the journal (http://dx.doi.org/ 10.1136/openhrt-2015000366).

Received 20 November 2015 Accepted 24 February 2016

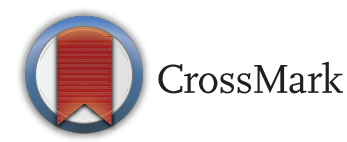

For numbered affiliations see end of article.

Correspondence to Dr Kazuo Chin; chink@kuhp.kyoto-u.ac.jp

\section{ABSTRACT}

Background: Both adaptive servoventilation (ASV) and nocturnal oxygen therapy improve sleep disordered breathing (SDB), but their effects on cardiac parameters have not been compared systematically. Methods and results: 43 patients with chronic heart failure (CHF; left ventricular ejection fraction (LVEF) $\leq 50 \%$ ) with SDB were randomly assigned to undergo ASV $(n=19$, apnoea hypopnoea index $(A H I)=34.2 \pm 12.1 / h)$ or oxygen therapy ( $n=24,36.9 \pm 9.9 / h)$ for 3 months. More than $70 \%$ of SDB events in both groups were central apnoeas or hypopnoeas. Although nightly adherence was less for the ASV group than for the oxygen group (4.4 \pm 2.0 vs $6.2 \pm 1.8 \mathrm{~h} /$ day, $\mathrm{p}<0.01$ ), the improvement in $\mathrm{AHI}$ was larger in the ASV group than in the oxygen group $(-27.0 \pm 11.5$ vs $-16.5 \pm 10.2 / \mathrm{h}, \mathrm{p}<0.01)$. The $\mathrm{N}$-terminal pro-brain natriuretic peptide (NT-proBNP) level in the ASV group improved significantly after titration $(1535 \pm 2224$ to $1251 \pm 2003 \mathrm{pg} / \mathrm{mL}, \mathrm{p}=0.01$ ), but increased slightly at follow-up and this improvement was not sustained $(1311 \pm 1592 \mathrm{pg} / \mathrm{mL}, p=0.08)$. Meanwhile, the level of plasma NT-proBNP in the oxygen group did not show a significant change throughout the study (baseline 1071 \pm 1887 , titration $980 \pm 1913$, follow-up $1101 \pm 1888 \mathrm{pg} / \mathrm{mL}$, $p=0.19$ ). The significant difference in the changes in the NT-proBNP level throughout the study between the 2 groups was not found $(p=0.30)$. Neither group showed significant changes in echocardiographic parameters.

Conclusions: Although ASV produced better resolution of SDB in patients with CHF as compared with oxygen therapy, neither treatment produced a significant improvement in cardiac function in the short term. Although we could not draw a definite conclusion because of the small number of participants, our data do not seem to support the routine use of ASV or oxygen therapy to improve cardiac function in patients with $\mathrm{CHF}$ with SDB.

Trial registration number NCT01187823 (http://www. clinicaltrials.gov).

\section{INTRODUCTION}

Sleep disordered breathing (SDB) is an independent risk for mortality among patients

\section{KEY QUESTIONS}

What is already known about this subject?

- The benefits of treatment of sleep disordered breathing (SDB) for cardiac function in patients with chronic heart failure (CHF) remain controversial.

What does this study add?

- This clinical randomised trial compared the effects of adaptive servoventilation (ASV) and nocturnal oxygen therapy on patients with CHF with SDB. While ASV produced better resolution of SDB in patients with CHF as compared with oxygen therapy, neither treatment could produce a significant improvement in cardiac function.

How might this impact on clinical practice?

- Our data did not support routine use of ASV or oxygen therapy to improve cardiac function in patients with CHF with SDB.

with chronic heart failure $(\mathrm{CHF})^{1-4}$ and the clinical effects of several SDB treatment modalities, such as continuous positive airway pressure (CPAP) and adaptive servoventilation (ASV), have been investigated..$^{5-8}$ Two previous randomised controlled trial (RCT) studies reported that ASV improved SDB and cardiac function more effectively than did CPAP. ${ }^{9}{ }^{10}$ In one of those trials, ASV showed better nightly adherence than CPAP, which was considered to be one of the reasons for the superior effects of ASV over CPAP. However, a recent large RCT showed that all-cause and cardiovascular mortality were both increased with ASV therapy. ${ }^{11}$ Thus, the effects of ASV for patients with CHF with SDB remain controversial.

On the other hand, although nocturnal oxygen therapy also decreases the severity of $\mathrm{SDB}$ in patients with $\mathrm{CHF}^{12}$ the benefits of oxygen therapy on cardiac function have 
rarely been compared with those of ASV. Teschler $e t a l^{13}$ showed that the effect of ASV on the apnoea hypopnoea index (AHI) was superior to that of oxygen therapy, but the two treatment modalities had similar effects on hypoxaemia during sleep. Since SDB is thought to be detrimental to patients with CHF, mainly because of hypoxaemia, it is possible that oxygen therapy produces positive effects on cardiac function similar to ASV. ${ }^{14} 15$ Further, oxygen therapy showed quite good compliance $(7-8 \mathrm{~h} /$ night $)$ in patients with CHF. $^{16}$ Although Campbell et $a l^{17}$ compared the effects of ASV and oxygen therapy on central sleep apnoea in seven patients with CHF, a trial with a larger sample size is warranted. We therefore hypothesised that the suboptimal effect of oxygen therapy on SDB might be counterbalanced by better adherence as compared with ASV, resulting in similar effects of both treatments on cardiac function. We thus performed an RCT to compare the clinical effects of these two modalities in patients with CHF. In addition, since body fluid balance and body composition are associated with the pathophysiology of both SDB and $\mathrm{CHF}^{18-20}$ we also investigated whether SDB treatments affect these variables.

\section{METHODS}

\section{Patients screening}

Candidates with $\mathrm{CHF}$ for participation in the trial were consecutively screened in Kyoto University Hospital on the basis of the following criteria: (1) age 20-80 years; (2) CHF defined as LVEF of $\leq 50 \%$ on echocardiography; (3) AHI of $\geq 20 / \mathrm{h}$ with more than $15 \%$ of respiratory events being central; and (4) receiving a maximal cardiac medication regimen. The exclusion criteria were (1) any changes to cardioactive drug prescriptions, including diuretics in the prior 6 weeks; (2) admission for deterioration of heart failure or ischaemic heart diseases in the prior 6 weeks; (3) previous use of CPAP, ASV or nocturnal oxygen therapy for SDB; (4) being on renal dialysis; (5) history of stroke with neurological deficit; and (6) clinically unstable CHF judged by the attending cardiologists. First, potential candidates were consecutively screened from the heart failure clinic and they were invited to undergo screening for SDB by in-laboratory polysomnography (PSG). We invited patients both with and without CHF symptoms. Those whose PSG findings fulfilled the above criteria proceeded to the randomisation. This study was approved by the Ethics Committee of the study institute, and written informed consent was obtained from all patients. This trial was registered at http://www.clinicaltrials.gov (NCT01187823).

\section{Sleep study}

Diagnosis of SDB was confirmed by PSG (SomnoStar pro, Cardinal Health, Dublin, Ohio, USA; or Alice 4, Philips Respironics, Murrysville, Pennsylvania, USA). Surface electrodes were attached using standard techniques to obtain an electro-oculogram, electromyogram of the chin and a 12-lead EEG. Sleep stages were defined according to the criteria of Rechtschaffen and Kales. ${ }^{21}$ Respiratory efforts were monitored by calibrated respiratory inductive plethysmography. Airflow was monitored by a nasal pressure transducer and supplemented by an oronasal thermal sensor. Arterial oxygen saturation $\left(\mathrm{SpO}_{2}\right)$ was monitored continuously with a pulse oximeter. According to the previous study, central sleep apnoea was defined as the absence of tidal volume for $10 \mathrm{~s}$ or more without thoracoabdominal motion, and central hypopnoea was defined as a reduction of $50 \%$ or more in tidal volume from baseline for $10 \mathrm{~s}$ or more without airflow limitation, as detected by the measurement of nasal pressure..$^{5}$ Apnoea and hypopnoea were categorised as obstructive if there was out-of-phase motion of the rib cage and abdomen, or if airflow limitation was present. Respiratory events with both central and obstructive components were categorised as obstructive. AHI values were expressed as the number of episodes of apnoea and hypopnoea per hour over the total sleep time. The 3\% oxygen desaturation index (ODI) was defined as the number of desaturations of $3 \%$ or more per hour of sleep. The length of time that $\mathrm{SpO}_{2}$ was less than $90 \%$ during sleep was also calculated for each patient. The analysis of each sleep study was performed in a blinded manner by four experienced sleep technicians.

\section{Randomisation, intervention and follow-up}

Eligible patients were randomly assigned to the ASV or oxygen therapy group and then admitted for two nights for treatment titration. The randomisation was conducted by the data-coordinating centre in a blind manner, stratifying for two factors (age: $>66$ or $\leq 66$ years; LVEF: $>40 \%$ or $\leq 40 \%$ ). The attending physicians and patients were not blind to the study treatment.

The ASV instrument (BiPAP autoSV Advanced, Philips Respironics) used in the present study was able to adjust both pressure support (PS) and expiratory positive airway pressure (EPAP) automatically within the predetermined range. ${ }^{22}$ During the first night of titration, minimum and maximum EPAPs were determined mainly to abolish obstructive respiratory events. During the second night, the minimum PS was set to $0 \mathrm{~cm} \mathrm{H}_{2} \mathrm{O}$ and the maximum $\mathrm{PS}$ to $12 \mathrm{~cm} \mathrm{H}_{2} \mathrm{O}$ (or not higher than the maximum that the patient could tolerate) to optimally abolish central respiratory events. The mandatory breath rate was set as an automatic or fixed rate of $>10$ breaths/min.

For patients allocated to oxygen therapy, during the second PSG, the oxygen rate was adjusted to remain in the range of $2-4 \mathrm{~L} / \mathrm{min}$ to keep patients' $\mathrm{SpO}_{2}$ level at 95-99\% for as long as possible to prevent both hypo-oxaemia and hyperoxaemia. After the second PSG was complete, the amount of $\mathrm{O}_{2}$ delivered during the following treatment period was determined in each case. After the treatment titration, patients were instructed to 
use the allocated treatment at home as much as possible.

Three months after the titration, patients underwent a third sleep study to evaluate the effect of the treatments. We also recorded the usage time of the ASV device or oxygen concentrator by reading the time counter on the instrument.

\section{Measurements}

Cardiovascular parameters

The primary outcome was change in LVEF. Echocardiography was performed at baseline and at follow-up by a single experienced echocardiographer who was blind to the patient's treatment allocation. LVEF was calculated using a modified Simpson's method. At the same time, 6 min walking distance and quality of life (QoL), as measured by the Minnesota Living with Heart Failure Questionnaire (MLHFQ), were also quantified.

Blood samples were drawn in the morning following PSG. The level of plasma $N$-terminal pro-brain natriuretic peptide (NT-proBNP) was measured at baseline, following the titration and after the 3-month PSG.
Body fluid balance and body composition

Anthropometric parameters, blood pressure (BP) and body composition were measured in the morning following PSG. The body composition of each participant was examined by using a bioelectrical impedance analysis (BIA) instrument (Inbody s20, BIOSPACE, Seoul, South Korea) at baseline and at follow-up. This is a multifrequency impedance plethysmograph body composition analyser, which takes readings from the body using eightpoint tactile electrodes. The detailed principles of measurement of this device are provided in the online supplementary data. By adopting the proprietary algorithms, the amount of total body water (TBW), extracellular water (ECW), body fat mass and lean body fat mass were recorded. On the basis of a previous study, ${ }^{23}$ the ratio of ECW to TBW as a surrogate for fluid overload was also calculated. According to the manufacturer's guidelines, these measurements were not performed in seven participants (four ASV and three oxygen group) with implanted electrical devices.

\section{Sample size and statistical analysis}

According to the previous studies examining the effects of intervention for SDB on cardiac function, ${ }^{12}$ a change in

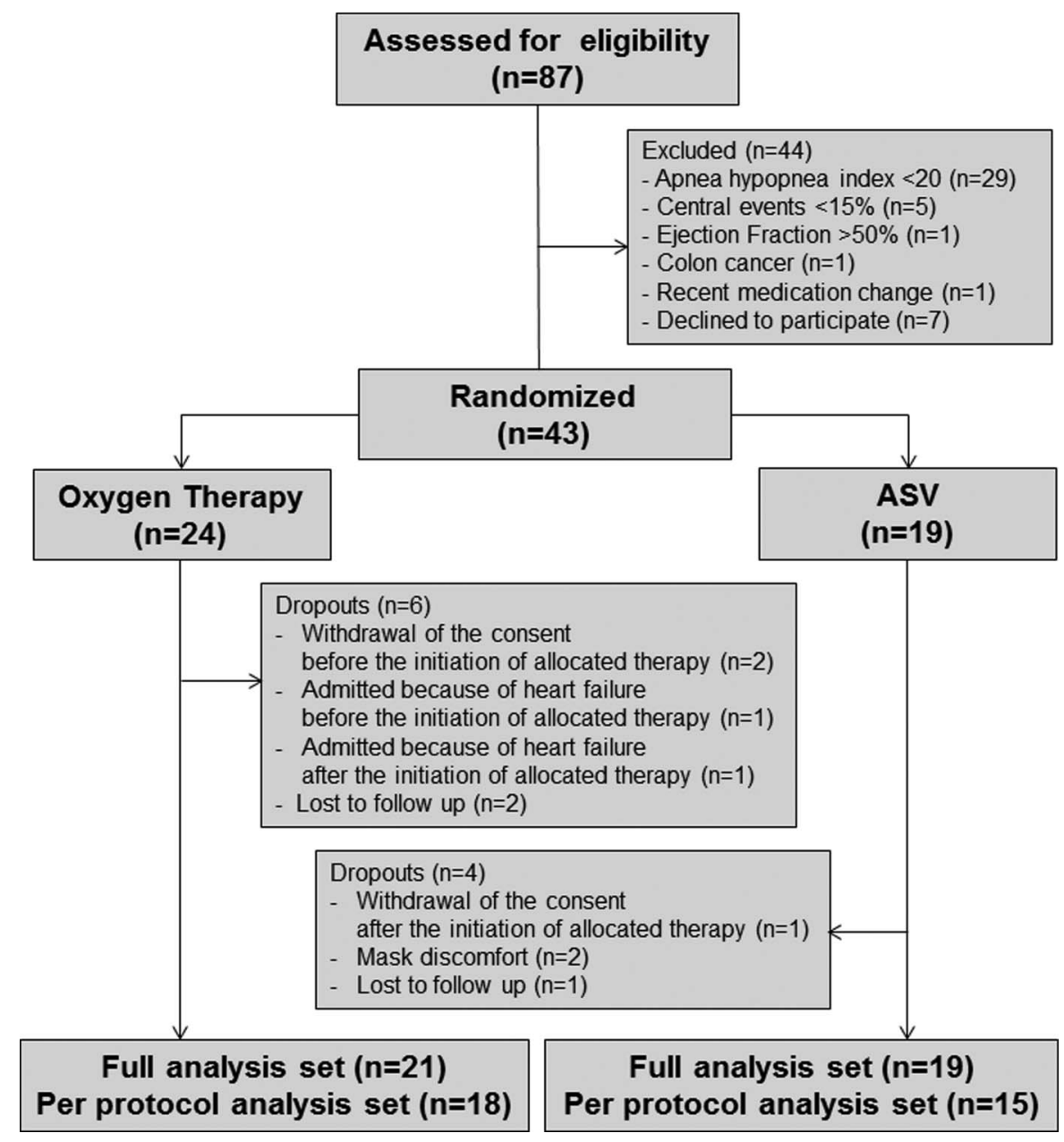

Figure 1 Trial design. ASV, adaptive servo ventilation. 
LVEF (ie, $\geq 4 \%$ ) between the two groups was determined to indicate a clinically relevant difference. It was calculated that 17 patients per group would be needed to detect this difference with an SD of 4.0, an $\alpha$ value of 0.05 and $80 \%$ power using two-sided significance testing. The efficacy analyses were performed on the full analysis set (FAS), which included all patients who used the allocated therapy for at least one night at home. Missing values for the outcome analysis were input by adopting the procedure of last observation carried forward procedure. The perprotocol analysis set (PPAS), which included only patients who completed the study course, was also analysed.

Background data and changes in parameters during the study course were compared between the two groups using the unpaired t test or Mann-Whitney $\mathrm{U}$ test for continuous variables. The $\chi^{2}$ test or Fisher's exact test was used to compare categorical variables. The paired $t$ test and Wilcoxon signed rank test were used to evaluate the changes in parameters within the same group. Repeated measure analyses of variance with post hoc pairwise comparison were used to compare the changes in AHI, 3\% ODI and log-transformed NT-proBNP level within the same group and between two groups. A twotailed $p$ value of $<0.05$ was considered statistically significant. All statistical analyses were performed using JMP V.11 (SAS Institute Inc, Cary, North Carolina, USA) and R software (http://www.r-project.org/).

\section{RESULTS}

The flow of patients through the trial is shown in figure 1. Eighty-seven patients were screened, and 43 patients were randomised to receive ASV $(n=19)$ or oxygen therapy $(n=24)$. The imbalance in the total number happened because of the imbalance in each strata by chance. Twenty-one patients in the oxygen group and all 19 in the ASV group used the allocated treatment for at least one night and were included in the FAS. Three patients in the oxygen group were excluded from the FAS: two of them withdrew their consent, and one was admitted owing to deteriorated heart failure before the start of the allocated treatment. Among 40 patients in the FAS, 18 patients in the oxygen group and 15 in the ASV group completed the study protocol and were included in the PPAS. Although the number of patients in the PPAS did not reach the goal, we had to stop recruiting patients because of financial constraints. Patients with primary valvular heart disease were not enrolled. No changes were made to the prescriptions of patients in the PPAS during the course of the study.

The background data of the FAS at baseline are shown in table 1. Although body mass index (BMI) was significantly lower in the ASV group than in the oxygen group, no other differences in these variables were found between the two groups. The detailed data for the echocardiographic and PSG parameters at baseline are shown in table 2 and online supplementary table S1, respectively.

Both ASV and oxygen therapy decreased AHI significantly (ASV: baseline 34.2 \pm 12.1 , titration 10.0 \pm 10.2 , follow-up $7.2 \pm 5.9 / \mathrm{h}, \mathrm{p}<0.01$; oxygen: baseline $36.9 \pm 9.9$, titration 19.5 \pm 11.0 , follow-up $19.4 \pm 8.4 / \mathrm{h}, \quad \mathrm{p}<0.01)$. However, the improvement in AHI was significantly

Table 1 Clinical background of study participants: full analysis set

\begin{tabular}{|c|c|c|c|}
\hline & ASV $(n=19)$ & Oxygen $(n=21)$ & p Value \\
\hline Male, n (\%) & $17(89.4)$ & $17(81.0)$ & 0.44 \\
\hline Age, years & $68 \pm 9$ & $69 \pm 9$ & 0.91 \\
\hline Body mass index, $\mathrm{kg} / \mathrm{m}^{2}$ & $22.9 \pm 2.9$ & $24.7 \pm 2.4$ & 0.04 \\
\hline NYHA classification (I/II/III), n & $0 / 14 / 5$ & $1 / 14 / 6$ & 0.50 \\
\hline \multicolumn{4}{|l|}{ Main aetiology of heart failure } \\
\hline Old myocardial infarction, n (\%) & $10(52.6)$ & $10(47.6)$ & \\
\hline Dilative cardiomyopathy, n (\%) & $9(47.4)$ & $9(42.8)$ & \\
\hline Hypertrophic cardiomyopathy, n (\%) & $0(0)$ & $1(4.8)$ & \\
\hline Sarcoidosis, n (\%) & $0(0)$ & $1(4.8)$ & 0.47 \\
\hline History of atrial fibrillation (\%) & $4(21.1)$ & $3(14.3)$ & 0.69 \\
\hline \multicolumn{4}{|l|}{ Medication } \\
\hline$\beta$-blocker, n (\%) & $14(73.7)$ & $18(85.7)$ & 0.44 \\
\hline Diuretics, n (\%) & $10(52.6)$ & $10(47.6)$ & 1.00 \\
\hline Ca-blocker, n (\%) & $3(15.8)$ & $3(14.3)$ & 1.00 \\
\hline ACE inhibitor/ARB, $n(\%)$ & $13(68.4)$ & $17(81.0)$ & 0.47 \\
\hline Amiodarone, $\mathrm{n}(\%)$ & $2(10.5)$ & $1(4.8)$ & 0.60 \\
\hline Implanted biventricular pacemaker or cardiac defibrillator, n (\%) & $4(21.1)$ & $3(14.3)$ & 0.58 \\
\hline NT-proBNP, pg/mL & $1200(356-1720)$ & $446(195-1160.5)$ & 0.10 \\
\hline Apnoea hypopnoea index, /h & $34.2 \pm 12.1$ & $36.9 \pm 9.9$ & 0.45 \\
\hline Central/total apnoea hypopnoea index, per cent & $83.1 \pm 15.7$ & $73.1 \pm 26.2$ & 0.16 \\
\hline $3 \%$ oxygen desaturation index, $/ \mathrm{h}$ & $28.2 \pm 15.6$ & $32.7 \pm 11.9$ & 0.30 \\
\hline
\end{tabular}

Values are expressed as mean $\pm \mathrm{SD}$ or median (first-third quartile).

ARB, angiotensin receptor blocker; ASV, adaptive servoventilation; NT-proBNP, N-terminal pro-brain natriuretic peptide; NYHA, New York Heart Association. 
greater in the ASV group than in the oxygen group $(\mathrm{p}=0.01)$. Meanwhile, although both groups showed a decrease in $3 \%$ ODI (ASV: baseline 28.2 \pm 15.6 , titration 3.0 \pm 2.4 , follow-up $3.9 \pm 4.1 / \mathrm{h}, \mathrm{p}<0.01$; oxygen: baseline $32.7 \pm 11.9$, titration $3.3 \pm 5.6$, follow-up $2.6 \pm 5.7 / \mathrm{h}, \mathrm{p}<0.01$ ), the change in $3 \%$ ODI throughout the study did not differ significantly between the two groups $(p=0.56)$ (figure 2). ASV settings and the changes in other PSG parameters in each group are shown in table 3 and online supplementary table $\mathrm{S} 1$, respectively. For all patients in the oxygen group, $3 \mathrm{~L} / \mathrm{min}$ of $\mathrm{O}_{2}$ was considered to be optimal for their SDB treatment and it was administered to all of them for 3 months. The number of hours of treatment usage was higher in the oxygen group than in the ASV group (ASV 4.4 \pm 2.0 vs oxygen 6.2 $\pm 1.8 \mathrm{~h} /$ day, $\mathrm{p}<0.01$; table 3 ).

With regard to cardiac function, neither group showed a significant change in LVEF and no significant difference in the changes in the echocardiographic parameters was found between the two groups (table 2). Systolic BP decreased significantly in the ASV group, whereas the MLHFQ score showed a decreasing trend in both groups (table 4 ).

The level of plasma NT-proBNP in the oxygen group did not show a significant change throughout the study (baseline 1071 \pm 1887 , titration 980 \pm 1913 , follow-up 1101

Table 2 Echocardiographic parameters at baseline and at 3 months follow-up: full analysis set

\begin{tabular}{|c|c|c|c|}
\hline & ASV $(n=19)$ & Oxygen $(n=21)$ & $\mathbf{p}^{*}$ Value \\
\hline \multicolumn{4}{|c|}{ Left ventricular ejection fraction, per cent } \\
\hline Baseline & $35.2 \pm 10.0$ & $36.0 \pm 10.3$ & \multirow[t]{2}{*}{0.80} \\
\hline 3 months & $35.6 \pm 11.8$ & $37.0 \pm 11.4$ & \\
\hline$\triangle$ & $0.3 \pm 4.2$ & $1.0 \pm 4.7$ & 0.66 \\
\hline \multicolumn{4}{|c|}{ Left ventricular endo-diastolic diameter, $\mathrm{mm}$} \\
\hline Baseline & $58.9 \pm 9.3$ & $60.3 \pm 7.9$ & \multirow[t]{2}{*}{0.61} \\
\hline 3 months & $58.7 \pm 9.1$ & $60.0 \pm 9.5$ & \\
\hline$\triangle$ & $-0.2 \pm 2.4$ & $-0.3 \pm 2.8$ & 0.85 \\
\hline \multicolumn{4}{|c|}{ Left ventricular endo-systolic diameter, $\mathrm{mm}$} \\
\hline Baseline & $48.8 \pm 10.6$ & $50.9 \pm 10.3$ & \multirow[t]{2}{*}{0.54} \\
\hline 3 months & $48.4 \pm 11.2$ & $50.1 \pm 12.5$ & \\
\hline$\triangle$ & $-0.5 \pm 2.4$ & $-0.8 \pm 3.7$ & 0.77 \\
\hline \multicolumn{4}{|c|}{ Left ventricular endo-diastolic volume mL } \\
\hline Baseline & $171.7 \pm 59.4$ & $160.4 \pm 72.9$ & \multirow[t]{2}{*}{0.60} \\
\hline 3 months & $166.1 \pm 52.1 \dagger$ & $171.2 \pm 84.9$ & \\
\hline$\triangle$ & $-5.4 \pm 12.7$ & $10.8 \pm 29.3$ & 0.06 \\
\hline \multicolumn{4}{|c|}{ Left ventricular endo-systolic volume, mL } \\
\hline Baseline & $112.3 \pm 57.2$ & $108.9 \pm 70.2$ & \multirow[t]{2}{*}{0.87} \\
\hline 3 months & $110.5 \pm 51.7$ & $114.4 \pm 75.2$ & \\
\hline$\triangle$ & $-1.7 \pm 10.7$ & $5.5 \pm 21.9$ & 0.20 \\
\hline \multicolumn{4}{|c|}{ Left atrium diameter, mm } \\
\hline Baseline & $43.9 \pm 6.6$ & $46.5 \pm 8.5$ & \multirow[t]{2}{*}{0.29} \\
\hline 3 months & $44.8 \pm 6.3$ & $46.8 \pm 7.7$ & \\
\hline$\triangle$ & $0.9 \pm 2.3$ & $0.3 \pm 3.1$ & 0.51 \\
\hline
\end{tabular}

Values are expressed as mean \pm SD.

* $p$ Value for comparison between the ASV and oxygen groups. $t p<0.10$ versus baseline within the same group.

ASV, adaptive servoventilation. $\pm 1888 \mathrm{pg} / \mathrm{mL}, \mathrm{p}=0.19)$. The NT-proBNP level in the ASV group decreased significantly after titration $(1535 \pm 2224$ to $1251 \pm 2003 \mathrm{pg} / \mathrm{mL}, \mathrm{p}=0.01$ ), but increased slightly at follow-up and this improvement was not sustained (1311 $\pm 1592 \mathrm{pg} / \mathrm{mL}, \mathrm{p}=0.08)$. A significant difference in the changes in the NT-proBNP level between the two groups was not found $(\mathrm{p}=0.30$; figure 3$)$.

The ASV group showed a small but significant increase in body weight $(61.3 \pm 12.6$ to $62.4 \pm 12.6 \mathrm{~kg}, \mathrm{p}=0.02)$. From the BIA analysis in patients without an implanted device, the amount of both ECW and TBW did not change significantly in either group, but the amount of body fat increased in the ASV group (16.1 \pm 6.4 to 17.1 $\pm 6.2 \mathrm{~kg}, \mathrm{p}=0.02$; table 5 ).

Analyses of the PPAS are shown in the online supplementary data (see online supplementary tables S2-6 and figures S1 and 2). Overall, the results of the PPAS were similar to those of the FAS except that the decrease in LVEDV from baseline to follow-up was significantly greater in the ASV group than in the oxygen group $(-7.1 \pm 13.9$ vs $12.6 \pm 31.4 \mathrm{~mL}, \mathrm{p}=0.04$; see online supplementary table S3).

\section{DISCUSSION}

In the present trial for patients with CHFs with SDB, although ASV showed greater improvement in AHI as compared with oxygen therapy, neither of them led to an improvement in the plasma NT-proBNP level or LVEF after 3 months of treatment. Although previous trials have reported conflicting results regarding the effect of ASV or oxygen therapy on LVEF and plasma NT-proBNP level, ${ }^{8} 1011 \quad 162425$ the reasons for these inconsistent results remain to be elucidated.

As compared with cohorts in previous trials, ${ }^{9-11} 2425$ the proportion of patients using cardiac medication such as diuretics, ACE inhibitor and angiotensin receptor blocker was smaller in the present cohort, even though their LVEF scores and disease severity in terms of New York Heart Association (NYHA) classification were similar. This suggests that this study included more clinically stable patients with CHF as compared with previous studies. Therefore, it is possible that the effect of SDB treatments on cardiac function might vary depending on subtle differences in the clinical condition of the study population and on the severity of CHF. However, Zhao $e t a l^{26}$ and Sin $e t a l^{27}$ reported a similar frequency of cardiac medication use in their cohort with $\mathrm{CHF}$; thus, the rate of medication use among the present cohort does not seem to differ substantially from that among patients with $\mathrm{CHF}$ in the real world. Investigations to identify the characteristics of patients with CHF who may benefit from the treatments of SDB are warranted.

Further, the proportion of central SDB events was relatively higher in the present cohort than in previous ones. ${ }^{10} 2425$ Another study has suggested that the BMI of patients with CHF in Japan is lower than that in 

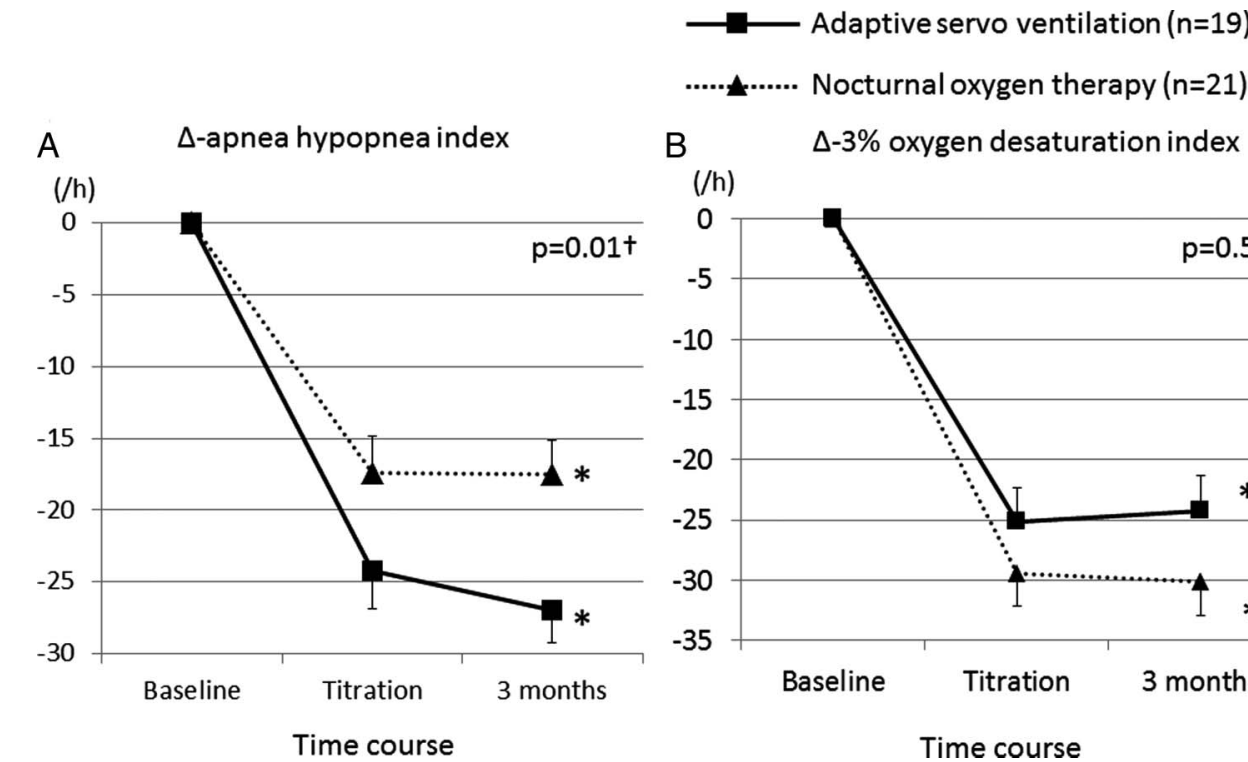

B $\Delta-3 \%$ oxygen desaturation index

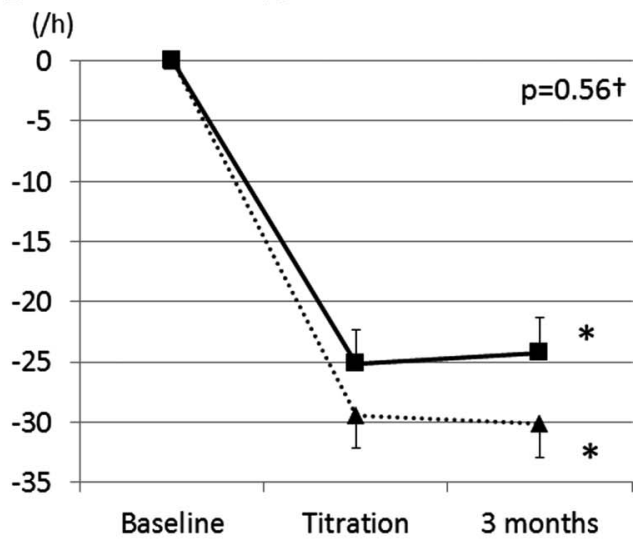

Figure 2 ( $\mathrm{A}$ and $\mathrm{B}$ ) Changes in the apnoea hypopnoea index (AHI) and 3\% oxygen desaturation index (ODI) from baseline to treatment titration and 3 months of therapy: full analysis set. Plotted line graphs indicate the mean $\pm S E$ at each assessment. *One-way repeated measure analyses of variance (ANOVA) showed that both adaptive servoventilation (ASV) and oxygen therapy significantly decreased AHI (ASV: baseline 34.2 \pm 12.1 , titration 10.0 \pm 10.2 , follow-up 7.2 $\pm 5.9 / \mathrm{h}$, p $<0.01$; oxygen: baseline $36.9 \pm 9.9$, titration $19.5 \pm 11.0$, follow-up $19.4 \pm 8.4 / \mathrm{h}, \mathrm{p}<0.01$ ) and $3 \%$ ODI (ASV: baseline $28.2 \pm 15.6$, titration $3.0 \pm 2.4$, follow-up 3.9 $\pm 4.1 / \mathrm{h}, \mathrm{p}<0.01$; oxygen: baseline $32.7 \pm 11.9$, titration $3.3 \pm 5.6$, follow-up $2.6 \pm 5.7 / \mathrm{h}, \mathrm{p}<0.01$ ) within the same group. $\dagger$ Two-way measured ANOVA showed that a significant difference was found in the changes in $A H I(p=0.01)$ but not in $3 \%$ ODI ( $p=0.56)$ throughout the study between the two groups.

western countries. ${ }^{28}$ In fact, the participants' BMI was smaller in this study than in previous trials, and a higher BMI has been reported to be a predictive factor for obstructive sleep apnoea in patients with $\mathrm{CHF}^{26}{ }^{27}$ Therefore, this smaller BMI may be one of the reasons for the smaller number of obstructive SDB events observed in the present cohort as compared with previous ones. Since obstructive and central SDB events seem to affect CHF pathophysiology in different ways, the effect of SDB treatments on cardiac function can change depending on the type of SDB event. ${ }^{29}$

Even though neither therapy could improve the NT-proBNP level and LVEF, analysis of the PPAS revealed that the decrease in LVEDV was greater in the ASV group than in the oxygen group. In addition, the ASV group showed a significant decrease in the plasma NT-proBNP level following titration, whereas the oxygen group did not. These findings might be associated with reverse remodelling and suggest that not just preventing hypoxia but also normalising the breathing pattern during sleep is beneficial to decrease haemodynamic stress in patients with CHF. Positive pressure with ASV also might reduce left ventricular afterload by increasing intrathoracic pressure and reducing left ventricular transmural pressure in addition to reducing SDB events. ${ }^{30}$ Further, the ASV group showed a small but significant increase in body weight, and in a large proportion of cases, the increase was due to changes in body fat mass. Since higher body fat mass is associated with a better prognosis among patients with $\mathrm{CHF}^{19}$ this change might reflect a more favourable result in the ASV group than in the oxygen group. However, whether the implementation of ASV generated these changes is uncertain, and further studies investigating the effect of ASV on metabolic factors such as energy expenditure and food intake are warranted. Although these results seemed to suggest favourable effects of ASV, further trials with larger numbers of patients are required to establish definitive clinical strategies.

Recently, a large RCT found that ASV did not improve clinical outcomes among patients with CHF with

Table 3 ASV setting and treatment compliance

\begin{tabular}{|c|c|c|c|}
\hline & $\begin{array}{l}\text { ASV } \\
(n=19)\end{array}$ & $\begin{array}{l}\text { Oxygen } \\
(n=21)\end{array}$ & p Value \\
\hline \multicolumn{4}{|c|}{ Adaptive servo ventilation settings } \\
\hline $\begin{array}{l}\text { Minimum EPAP, } \\
\mathrm{cm} \mathrm{H}_{2} \mathrm{O}\end{array}$ & $4.4 \pm 0.8$ & - & - \\
\hline $\begin{array}{l}\text { Maximum EPAP, } \\
\mathrm{cm} \mathrm{H}_{2} \mathrm{O}\end{array}$ & $8.1 \pm 0.8$ & - & - \\
\hline $\begin{array}{l}\text { Minimum pressure } \\
\text { support, } \mathrm{cm} \mathrm{H}_{2} \mathrm{O}\end{array}$ & 0 & - & - \\
\hline $\begin{array}{l}\text { Maximum pressure } \\
\text { support, } \mathrm{cm} \mathrm{H}_{2} \mathrm{O}\end{array}$ & $8.0 \pm 0.7$ & - & - \\
\hline \multicolumn{4}{|l|}{ Treatment compliance } \\
\hline Hour of use, h/day & $4.4 \pm 2.0$ & $6.2 \pm 1.8$ & $<0.01$ \\
\hline
\end{tabular}


Table 4 Cardiac parameters at baseline and after 3 months of therapy: full analysis set

\begin{tabular}{|c|c|c|c|}
\hline & ASV $(n=19)$ & Oxygen $(n=21)$ & $p^{*}$ Value \\
\hline \multicolumn{4}{|c|}{ Systolic blood pressure, $\mathrm{mm} \mathrm{Hg}$} \\
\hline Baseline & $121.5 \pm 19.2$ & $120.5 \pm 15.4$ & 0.86 \\
\hline 3 months & $116.3 \pm 16.3 \dagger$ & $119.7 \pm 14.1$ & \\
\hline$\triangle$ & $-5.2 \pm 10.7$ & $-0.8 \pm 15.0$ & 0.30 \\
\hline \multicolumn{4}{|c|}{ Diastolic blood pressure, $\mathrm{mm} \mathrm{Hg}$} \\
\hline Baseline & $68.9 \pm 9.2$ & $70.6 \pm 10.3$ & 0.59 \\
\hline 3 months & $67.4 \pm 10.3$ & $69.0 \pm 9.6$ & \\
\hline$\triangle$ & $-1.5 \pm 9.4$ & $-1.6 \pm 12.8$ & 0.97 \\
\hline \multicolumn{4}{|c|}{ Heart rate, /m } \\
\hline Baseline & $65.4 \pm 12.1$ & $70.0 \pm 13.5$ & 0.27 \\
\hline 3 months & $63.9 \pm 12.4$ & $72.6 \pm 15.5$ & \\
\hline$\triangle$ & $-1.4 \pm 7.7$ & $2.6 \pm 10.4$ & 0.17 \\
\hline \multicolumn{4}{|l|}{$6 \mathrm{MWD}, \mathrm{m}$} \\
\hline Baseline & $468 \pm 78$ & $444 \pm 83$ & 0.81 \\
\hline 3 months & $465 \pm 105$ & $454 \pm 87 \ddagger$ & \\
\hline$\triangle$ & $-3 \pm 35$ & $10 \pm 23$ & 0.20 \\
\hline \multicolumn{4}{|c|}{ MLHFQ score } \\
\hline Baseline & $24.3 \pm 20.2$ & $28.4 \pm 23.2$ & 0.56 \\
\hline 3 months & $18.8 \pm 17.1 \neq$ & $23.9 \pm 21.5 \ddagger$ & \\
\hline$\triangle$ & $-5.4 \pm 13.7$ & $-4.5 \pm 11.6$ & 0.81 \\
\hline \multicolumn{4}{|c|}{$\begin{array}{l}\text { Values are expressed as mean } \pm S D \text {. } \\
\text { ASV, adaptive servoventilation; } 6 M W D, 6 \text { min walking distance; } \\
\text { MLHFQ, Minnesota Living with Heart Failure Questionnaire. } \\
\text { ” } p \text { Value for comparison between the ASV and oxygen groups. } \\
t p<0.05 \text { versus baseline within the same group. } \\
\ddagger p<0.10 \text { versus baseline within the same group. }\end{array}$} \\
\hline
\end{tabular}

predominantly central sleep apnoea. ${ }^{11}$ However, the ASV device adopted in this study differed from that in the large RCT. The algorithm for tracking patients' breathing was different in the two studies. In addition, the ASV device used in the large trial had fixed EPAP and more than $3 \mathrm{~cm} \mathrm{H} \mathrm{H}_{2} \mathrm{O}$ of PS, whereas the device in this study had auto-flexible EPAP and its minimum PS could be as low as $0 \mathrm{~cm} \mathrm{H}_{2} \mathrm{O}$. No previous study has compared clinical effects between these ASV devices, and the effects of ASV can vary depending on these conditions. Another large, ongoing RCT (ClinicalTrials.gov number, NCT01128816) is adopting the same ASV device as in this study and will help both to interpret the results of this study and to determine the clinical strategy for treating SDB in patients with CHF.

Overall, even though ASV seemed to produce more advantageous changes in SDB than oxygen therapy, these changes were not associated with an improvement in LVEF and NT-proBNP level in 3 months. Although we cannot draw a definite conclusion because of the small number of participants, our data did not seem to support routine use of ASV or oxygen therapy to improve cardiac function in patients with CHF with SDB. Further, in line with a recent large RCT showing negative clinical effects of ASV for patients with SDB,${ }^{11}$ we cannot routinely recommend ASV use for this type of cohort unless further studies first clarify the mechanisms underlying the

$\longrightarrow$ Adaptive servo ventilation $(n=19)$

.............. Nocturnal oxygen therapy $(n=21)$

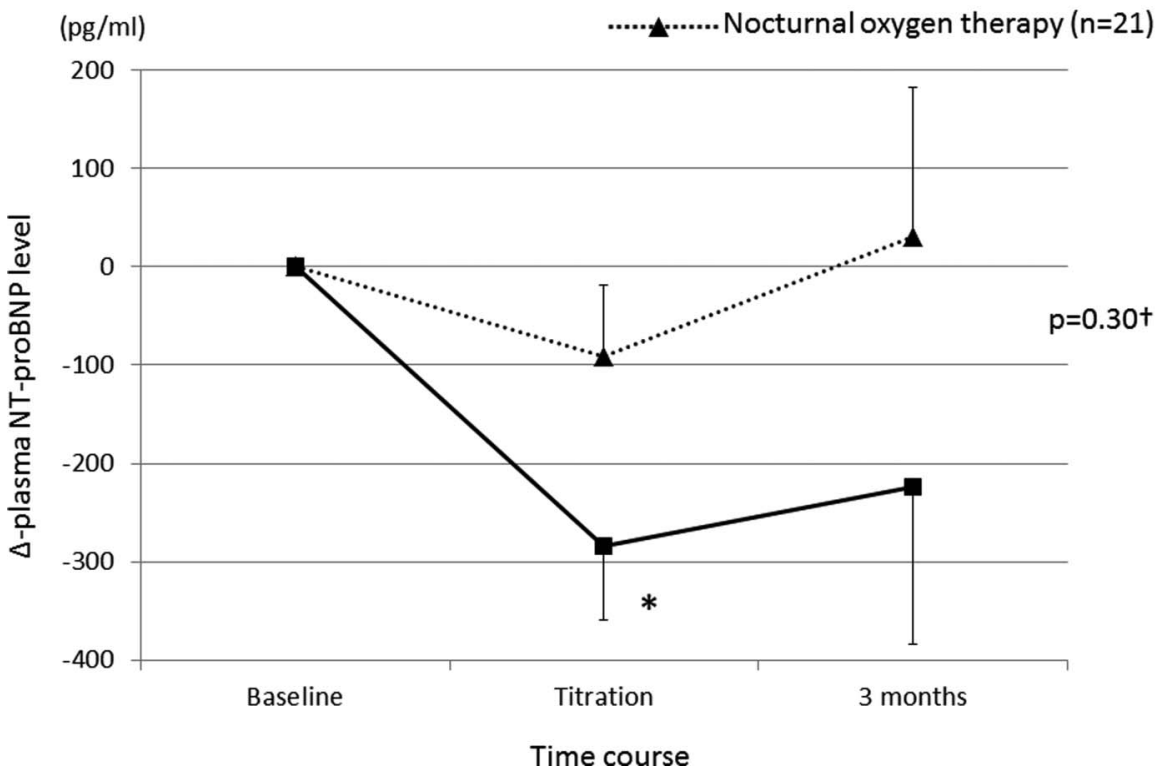

Figure 3 Changes in the plasma $N$-terminal pro-brain natriuretic peptide (NT-proBNP) level from baseline to treatment titration and 3 months of therapy: full analysis set. Plotted line graphs indicate the mean $\pm S E$ at each assessment. The changes in NT-proBNP level throughout the study were compared by one-way and two-way repeated measure analyses of variance with post hoc pairwise comparison within the same group and between the two groups, respectively, after NT-proBNP values were log-transformed. *In the adaptive servoventilation group, the plasma NT-proBNP level decreased significantly from baseline to titration $(1535 \pm 2224$ to $1251 \pm 2003 \mathrm{pg} / \mathrm{mL}, \mathrm{p}<0.01)$. At 3 months, it increased slightly and its change from baseline did not reach statistical significance $(1311 \pm 1592 \mathrm{pg} / \mathrm{mL}, \mathrm{p}=0.08)$. On the other hand, the oxygen group did not show a significant change throughout the study (baseline $1071 \pm 1887$, titration $980 \pm 1913$, follow-up $1101 \pm 1888 \mathrm{pg} / \mathrm{mL}, \mathrm{p}=0.19$ ). $†$ The difference in the change in NT-proBNP throughout the study between the two groups did not reach statistical significance $(p=0.30)$. 
Table 5 Changes in body composition measured by the bioimpedance analyser: full analysis set

\begin{tabular}{|c|c|c|c|}
\hline & ASV $(n=15)$ & Oxygen $(n=18)$ & $p^{*}$ Value \\
\hline \multicolumn{4}{|c|}{ Body mass index $\left(\mathrm{kg} / \mathrm{m}^{2}\right)$} \\
\hline Baseline & $22.8 \pm 3.0$ & $25.1 \pm 2.3$ & \multirow[t]{2}{*}{0.02} \\
\hline 3 months & $23.4 \pm 2.9 \dagger$ & $25.1 \pm 2.5$ & \\
\hline$\triangle$ & $0.5 \pm 0.7$ & $0.0 \pm 0.5$ & 0.04 \\
\hline \multicolumn{4}{|c|}{ Total body water $(\mathrm{L})$} \\
\hline Baseline & $33.3 \pm 5.2$ & $34.9 \pm 5.4$ & \multirow[t]{2}{*}{0.39} \\
\hline 3 months & $33.5 \pm 5.2$ & $35.0 \pm 5.6$ & \\
\hline$\triangle$ & $0.2 \pm 0.8$ & $0.1 \pm 0.7$ & 0.68 \\
\hline \multicolumn{4}{|c|}{ Extracellular water (L) } \\
\hline Baseline & $12.8 \pm 1.9$ & $13.6 \pm 2.2$ & \multirow[t]{2}{*}{0.29} \\
\hline 3 months & $12.9 \pm 1.9$ & $13.6 \pm 2.3$ & \\
\hline$\triangle$ & $0.1 \pm 0.3$ & $0.1 \pm 0.3$ & 0.60 \\
\hline \multicolumn{4}{|c|}{ Extracellular water/total body water (\%) } \\
\hline Baseline & $38.4 \pm 0.8$ & $38.8 \pm 0.9$ & \multirow[t]{2}{*}{0.19} \\
\hline 3 months & $38.5 \pm 0.7$ & $38.9 \pm 1.0$ & \\
\hline$\triangle$ & $0.1 \pm 0.3$ & $0.0 \pm 0.3$ & 0.45 \\
\hline \multicolumn{4}{|c|}{ Fat mass $(\mathrm{kg})$} \\
\hline Baseline & $16.1 \pm 6.4$ & $20.9 \pm 4.2$ & \multirow[t]{2}{*}{0.01} \\
\hline 3 months & $17.1 \pm 6.2 \dagger$ & $20.9 \pm 4.7$ & \\
\hline$\triangle$ & $1.0 \pm 1.5$ & $-0.1 \pm 1.0$ & 0.02 \\
\hline \multicolumn{4}{|c|}{ Lean fat mass $(\mathrm{kg})$} \\
\hline Baseline & $45.2 \pm 7.1$ & $47.4 \pm 7.3$ & \multirow[t]{2}{*}{0.41} \\
\hline 3 months & $45.5 \pm 7.1$ & $47.5 \pm 7.5$ & \\
\hline$\triangle$ & $0.4 \pm 1.1$ & $0.2 \pm 1.0$ & 0.56 \\
\hline $\begin{array}{l}\text { Values are exp } \\
{ }^{*} p \text { Value for } c 0 \\
t p<0.05 \text { versu } \\
\text { ASV, adaptive }\end{array}$ & $\begin{array}{l}\text { ssed as mean } \\
\text { parison betwee } \\
\text { oaseline within } \\
\text { ervo ventilation. }\end{array}$ & $\begin{array}{l}\text { D. } \\
\text { the ASV and oxyger } \\
\text { same group. }\end{array}$ & groups. \\
\hline
\end{tabular}

negative effects of ASV. On the other hand, with regard to resolution of SDB, oxygen therapy showed good adherence and a trend towards improving patient QoL. Since oxygen therapy did not show a significantly worse effect on cardiac parameters, compared with the baseline condition, it may be an acceptable alternative treatment for ASV among patients with CHF with SDB.

The limitations of this study should be considered. First, the number of patients was small and did not reach the determined goal. Further, since we did not include a control group with neither ASV nor oxygen therapy, we could not draw definite conclusions. To date, however, this study is the largest RCT comparing the effect of ASV and oxygen therapy on patients with CHF with SDB, and the results may be helpful to design future studies. Second, it was not possible for the attending physicians or patients to be blind to the therapy. However, since the sonographer and sleep technicians who scored PSG were blind to the treatment allocation, observer bias did not affect the results. Lastly, although we randomly allocated the treatments, the ASV group had a smaller BMI at baseline as compared with the oxygen group. Since a higher BMI is associated with a better prognosis for patients with $\mathrm{CHF}^{1920}$ the ASV group might have included patients with a worse condition as compared with the oxygen group, and this difference might have affected the response to the treatments.
In summary, although ASV suppressed SDB in patients with CHF more efficiently than did oxygen therapy, cardiac function did not change significantly in either group. Although a definite conclusion cannot be made because of the small number of participants, our data do not seem to support routine use of ASV or oxygen therapy to improve cardiac function in patients with CHF with SDB. Given the discrepant results among previous studies and the present one, further studies identifying patients with CHF who can benefit from SDB treatments are warranted.

\section{Author affiliations}

${ }^{1}$ Department of Respiratory Medicine, Graduate School of Medicine, Kyoto University, Kyoto, Japan

${ }^{2}$ Department of Cardiovascular Medicine, Graduate School of Medicine, Kyoto University, Kyoto, Japan

${ }^{3}$ Clinical Laboratory Medicine, Kyoto University Hospital, Kyoto, Japan ${ }^{4}$ Department of Cardiovascular Medicine, Kyoto Medical Centre, Kyoto, Japan ${ }^{5}$ Department of Cardiovascular Medicine, Kyoto Mitsubishi Hospital, Kyoto, Japan

${ }^{6}$ Department of Cardiovascular Medicine, Kitano Hospital, Osaka, Japan ${ }^{7}$ Department of EBM Research, Institute for Advancement of Clinical and Translational Research, Kyoto University Hospital, Kyoto, Japan

${ }^{8}$ Division of Sleep Medicine, Brigham and Women's Hospital and Harvard Medical School, Boston, Massachusetts, USA

${ }^{9}$ Department of Respiratory Care and Sleep Control Medicine, Graduate School of Medicine, Kyoto University, Kyoto, Japan

Acknowledgements The authors would like to thank Mr Kazuyuki Ueda, Ms Yuko Yamanishi, Natsuko Susukida and Nobuko Matsuura for their contribution in analysing the polysomnographic data. They also thank all of the physicians of the Department of Cardiovascular Medicine, Kyoto University Hospital, for helping the authors in inviting the patients to participate in the study.

Contributors KM contributed to the study design, collection of data, analysis and interpretation of data, and the writing of the manuscript. DPW, KU, MM and $\mathrm{KC}$ contributed to the study design and editing of the draft. TY evaluated the patients' echocardiography data. All other authors contributed to collection of data.

Funding This work was supported by Phillips-Respironics, Inc.

Competing interests KC declares that the Department of Respiratory Care and Sleep Control Medicine is funded by endowments from Philips Respironics, Teijin Pharma, Fukuda-lifetec Keiji and Fukuda Denshi to Kyoto University. DPW declares that he is a consultant for Philips Respironics and the Chief Scientific Officer for Apnicure, Inc.

Ethics approval Ethics Committee of Kyoto University Hospital.

Provenance and peer review Not commissioned; externally peer reviewed.

Data sharing statement No additional data are available.

Open Access This is an Open Access article distributed in accordance with the Creative Commons Attribution Non Commercial (CC BY-NC 4.0) license, which permits others to distribute, remix, adapt, build upon this work noncommercially, and license their derivative works on different terms, provided the original work is properly cited and the use is non-commercial. See: http:// creativecommons.org/licenses/by-nc/4.0/

\section{REFERENCES}

1. Schulz R, Blau A, Borgel J, et al. Sleep apnoea in heart failure. Eur Respir J 2007;29:1201-5.

2. Oldenburg O, Lamp B, Faber L, et al. Sleep-disordered breathing in patients with symptomatic heart failure: a contemporary study of prevalence in and characteristics of 700 patients. Eur J Heart Fail 2007;9:251-7. 
3. Javaheri S, Shukla $\mathrm{R}$, Zeigler $\mathrm{H}$, et al. Central sleep apnea, right ventricular dysfunction, and low diastolic blood pressure are predictors of mortality in systolic heart failure. J Am Coll Cardiol 2007:49:2028-34

4. Wang H, Parker JD, Newton GE, et al. Influence of obstructive sleep apnea on mortality in patients with heart failure. J Am Coll Cardiol 2007:49:1625-31.

5. Bradley TD, Logan AG, Kimoff RJ, et al. Continuous positive airway pressure for central sleep apnea and heart failure. $N$ Engl J Med 2005;353:2025-33.

6. Sharma BK, Bakker JP, McSharry DG, et al. Adaptive servoventilation for treatment of sleep-disordered breathing in heart failure: a systematic review and meta-analysis. Chest 2012;142:1211-21.

7. Pepperell JC, Maskell NA, Jones DR, et al. A randomized controlled trial of adaptive ventilation for cheyne-stokes breathing in heart failure. Am J Respir Crit Care Med 2003;168:1109-14

8. Hastings PC, Vazir A, Meadows GE, et al. Adaptive servo-ventilation in heart failure patients with sleep apnea: a real world study. Int $J$ Cardiol 2010;139:17-24.

9. Kasai T, Usui Y, Yoshioka T, et al. Effect of flow-triggered adaptive servo-ventilation compared with continuous positive airway pressure in patients with chronic heart failure with coexisting obstructive sleep apnea and cheyne-stokes respiration. Circ Heart Fail 2010;3:140-8.

10. Randerath WJ, Nothofer G, Priegnitz C, et al. Long-term auto-servoventilation or constant positive pressure in heart failure and coexisting central with obstructive sleep apnea. Chest 2012;142:440-7.

11. Cowie MR, Woehrle $\mathrm{H}$, Wegscheider $\mathrm{K}$, et al. Adaptive servo-ventilation for central sleep apnea in systolic heart failure. N Engl J Med 2015;373:1095-105.

12. Aurora RN, Chowdhuri S, Ramar K, et al. The treatment of central sleep apnea syndromes in adults: practice parameters with an evidence-based literature review and meta-analyses. Sleep 2012;35:17-40.

13. Teschler H, Dohring J, Wang YM, et al. Adaptive pressure support servo-ventilation: a novel treatment for cheyne-stokes respiration in heart failure. Am J Respir Crit Care Med 2001;164:614-19.

14. Gottlieb JD, Schwartz AR, Marshall J, et al. Hypoxia, not the frequency of sleep apnea, induces acute hemodynamic stress in patients with chronic heart failure. J Am Coll Cardiol 2009;54:1706-12.

15. Hu K, Li QQ, Yang J, et al. The role of high-frequency jet ventilation in the treatment of cheyne-stokes respiration in patients with chronic heart failure. Int J Cardiol 2006;106:224-31.
16. Sasayama S, Izumi T, Seino $\mathrm{Y}$, et al. Effects of nocturnal oxygen therapy on outcome measures in patients with chronic heart failure and cheyne-stokes respiration. Circ J 2006;70:1-7.

17. Campbell AJ, Ferrier K, Neill AM. The effect of oxygen versus adaptive pressure support servo-ventilation in patients with central sleep apnoea-cheyne stokes respiration and congestive heart failure. Intern Med J 2012;42:1130-6.

18. Yumino D, Redolfi S, Ruttanaumpawan $\mathrm{P}$, et al. Nocturnal rostral fluid shift: a unifying concept for the pathogenesis of obstructive and central sleep apnea in men with heart failure. Circulation 2010;121:1598-605.

19. Lavie CJ, Osman AF, Milani RV, et al. Body composition and prognosis in chronic systolic heart failure: the obesity paradox. Am J Cardiol 2003;91:891-4.

20. Lavie CJ, Alpert MA, Arena R, et al. Impact of obesity and the obesity paradox on prevalence and prognosis in heart failure. JACC Heart Fail 2013;1:93-102.

21. Rechtschaffen A, Kales A. A manual of standardized terminology, techniques and scoring system for sleep stages of human subjects. Washington DC: National Institutes of Health, 1968.

22. Javaheri S, Goetting MG, Khayat R, et al. The performance of two automatic servo-ventilation devices in the treatment of central sleep apnea. Sleep 2011;34:1693-8.

23. Liu $\mathrm{MH}$, Wang $\mathrm{CH}$, Huang $\mathrm{YY}$, et al. Edema index-guided disease management improves 6 -month outcomes of patients with acute heart failure. Int Heart J 2012;53:11-17.

24. Arzt M, Schroll S, Series F, et al. Auto-servoventilation in heart failure with sleep apnoea: a randomised controlled trial. Eur Respir $J$ 2013;42:1244-54

25. Toyama T, Seki R, Kasama S, et al. Effectiveness of nocturnal home oxygen therapy to improve exercise capacity, cardiac function and cardiac sympathetic nerve activity in patients with chronic heart failure and central sleep apnea. Circ J 2009;73:299-304.

26. Zhao ZH, Sullivan C, Liu ZH, et al. Prevalence and clinical characteristics of sleep apnea in Chinese patients with heart failure. Int J Cardiol 2007;118:122-3.

27. Sin DD, Fitzgerald F, Parker JD, et al. Risk factors for central and obstructive sleep apnea in 450 men and women with congestive heart failure. Am J Respir Crit Care Med 1999;160:1101-6.

28. Nochioka K, Shiba N, Kohno H, et al. Both high and low body mass indexes are prognostic risks in Japanese patients with chronic heart failure: implications from the CHART study. J Card Fail 2010;16:880-7.

29. Naughton MT. Cheyne-stokes respiration: friend or foe? Thorax 2012;67:357-60.

30. Haruki N, Takeuchi M, Kaku K, et al. Comparison of acute and chronic impact of adaptive servo-ventilation on left chamber geometry and function in patients with chronic heart failure. Eur $J$ Heart Fail 2011;13:1140-6. 